\title{
A STUDY OF CLINICAL PROFILE, RADIOLOGICAL FEATURES, ELECTROCARDIOGRAPHIC AND ECHOCARDIOGRAPHIC CHANGES IN CHRONIC COR PULMONALE IN A RURAL HOSPITAL
}

Sunil Babu M11, Praveen N², Vasudev Naik³

\section{HOW TO CITE THIS ARTICLE:}

Sunil Babu M, Praveen N, Vasudev Naik. "A study of clinical profile, radiological features, electrocardiographic and echocardiographic changes in chronic cor pulmonale in a rural hospital". Journal of Evolution of Medical and Dental Sciences 2013; Vol. 2, Issue 45, Nov ember 11; Page: 8827-8840.

ABSTRACT: BACKGROUND AND OBJECTIVES: To study the clinical profile, radiological features, electrocardiographic and echocardiographic changes in clinically proven cases of chronic cor pulmonale. METHODS: 50 patients who were diagnosed to have chronic cor pulmonale based on the inclusion criteria were selected from the medical wards of Adichunchanagiri Hospital and research centre, over a period of 2 years In all the selected patients detailed history and physical examination was noted and chest x-ray PA, 12 lead ECG and echocardiogram done. RESULTS: Among 50 patients admitted with chronic cor pulmonale, 45 were males and 5 were females. The peak incidence was found in the $4^{\text {th }}, 5^{\text {th }}$ and $6^{\text {th }}$ decades of life. Smoking was found to be a major cause for COPD and hence cor pulmonale. Among 50 patients 43 were smokers. Among 50 cases, (60\%) were diagnosed to have chronic bronchitis with or without emphysema. Chest x-ray showed details relevant to the clinical profile. ECG showed 46\% cases with RVH, 64\% with RAD, 26\% RBBB and 70\% with P pulmonale. Every patient showed echocardiographic features suggesting chronic cor pulmonale except 3 patients who showed global hypokinesia. DISCUSSION AND CONCLUSION: Many patients who had chronic cor pulmonale were found to have COPD as the underlying disease. Majority of the male patients were smokers in the present study. Echocardiogram was found to be a better diagnostic tool. Though ECG and chest x-ray can support the diagnosis, ECHO can be used as a non invasive, affordable investigation for accurate and early diagnosis of chronic cor pulmonale.

KEYWORDS: Chronic cor pulmonale; Clinical profile; Chest x-ray; ECG; Echocardiogram.

INTRODUCTION: Cor pulmonale is a synonym for pulmonary heart disease. The term "cor pulmonale" if broken into its constituents "cor" (heart) and "pulmo" (lungs), means cardiac involvement due to pulmonary diseases.

Chronic cor pulmonale is not a single disease entity but resulting secondary to many bronchopulmonary vascular disease and also from thoracic cage abnormalities.

Cor pulmonale accounts for 5-10\% of all heart diseases, $20-30 \%$ of all admissions for heart failure. The development of PAH has important prognostic implications, as it significantly increases the risk of hospitalization and is associated with reduced survival. ${ }^{1}$

The true prevalence of cor pulmonale is difficult to ascertain for two reasons. First, not all patients with chronic lung disease will develop cor pulmonale, and second, our ability to diagnose pulmonary hypertension and cor pulmonale by routine physical examination and laboratory testing is relatively insensitive. ${ }^{4}$

The reported incidence of the disease in different areas show wide disparities and may reflect these inconsistencies in the diagnostic terminology and conventions. These reports also 
indicate real variations in disease experience and may give important clues to those differences in local environment or ways of life which may underlie the geographical distribution of the disease.2,5.

Chronic cor pulmonale is recognized as a serious protracted, ultimately fatal human experience consuming frequently a large segment of the sufferers' life. Thus it constitutes a serious problem in public health and preventive medicine.2,3

So far as hospital admissions are concerned, high figures for the incidence of cor pulmonale among hosp admission for heart failure ranging from $16 \%$ to $38 \%$ have been reported from places such as Belgrade, Delhi, Prague and Sheffield. In most reported series more than $50 \%$ of cases are attributed to chronic bronchitis, asthma or emphysema, which constitute an ill defined group of diseases ay uncertain aetiology. ${ }^{6}$

So it is apparent that chronic cor pulmonale is of clinical significance of serious problem in public health and preventive incidence.5,6,7

Chronic cor pulmonale can be diagnosed clinically, radiologically, electrocardiographically and also by invasive techniques.

\section{AIMS \& OBJECTIVES}

1. To know the clinical profile in chronic cor pulmonale

2. To know the radiological features, electrocardiographic and echocardiographic changes in clinically proven cases of chronic cor pulmonale

METHODOLOGY: The subjects for the study were be selected from the cases admitted to the medical wards of SRI Adichunchangiri Hospital and research center, B G Nagara, during the time period September 2010 to August 2012.

Fifty representative cases were selected by simple random sampling method for the study.

Inclusion criteria: All patients were included in the study with chronic cor pulmonale of both the genders as cases. The diagnosis of chronic cor pulmonale was established by;

- Clinical history with cough with sputum, paroxysmal cough, dyspnoea, fluid retention with edema and sometimes ascitis, recurrent chest infections, cyanosis, fatigue, chest pain, near syncope, palpitation.

- General physical examination suggesting RVF.

- Radiological examination, electrocardiographic and echocardiographic changes associated with chronic cor pulmonale.

\section{Exclusion criteria:}

- Patients with primary involvement of left side of the heart.

- Patients with valvular or myocardial disease.

- Patients with arterial occlusive disease from emboli.

- Patients with primary pulmonary hypertension.

- Patients with congenital heart disease.

- Patients with congenital heart diseases with reversal of shunt 
RESULTS: Following were the results obtained in our study:

\section{Age Distribution:}

\begin{tabular}{|c|c|c|}
\hline Age & No. of cases & Percentage \\
\hline $30-39$ & 7 & 14 \\
\hline $40-49$ & 10 & 20 \\
\hline $50-59$ & 23 & 46 \\
\hline $60-69$ & 6 & 12 \\
\hline $70-79$ & 4 & 8 \\
\hline
\end{tabular}

Table 1: Age distribution

Majority of the cases were in age between 40 and 59. Mean age-53 years

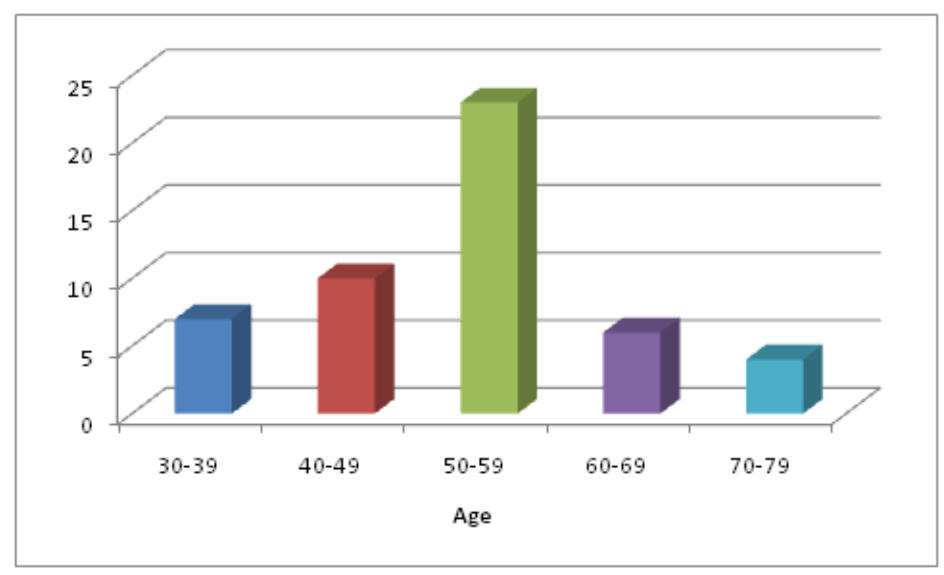

Graph 1: Age distribution

\section{Sex Distribution:}

\begin{tabular}{|l|c|c|}
\hline \multicolumn{1}{|c|}{ Sex } & No. of cases & Percentage \\
\hline Male & 45 & 90 \\
\hline Female & 5 & 10 \\
\hline \multicolumn{2}{|c|}{ Table 2: Sex distribution } \\
\hline
\end{tabular}

Male preponder ance was found in our study.

\section{Occupational Incidence:}

\begin{tabular}{|l|c|c|}
\hline Occupation & No of cases & Percentage \\
\hline Coolie & 23 & 46 \\
\hline Agriculturist & 16 & 32 \\
\hline Housewife & 5 & 10 \\
\hline Others & 6 & 12 \\
\hline \multicolumn{2}{|c|}{ Table 3: Occupation } \\
\hline
\end{tabular}


The bulk of the cases were from low socio-economic status since our hospital caters the rural population.

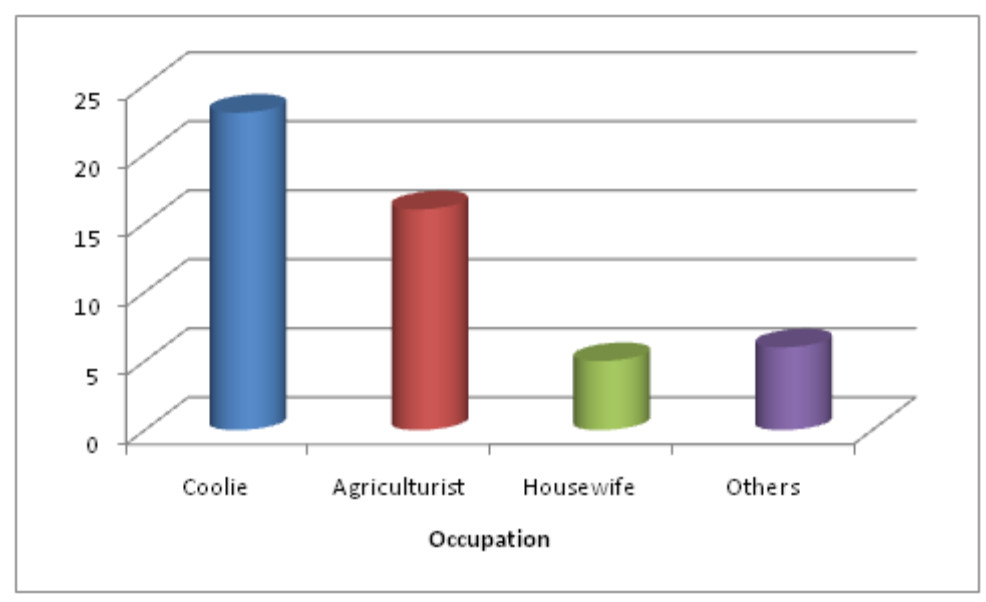

Graph 2: Occupation

Smoking 43[86\%] of male patients were smokers, $>10$ cigarettes or beedis per day [range$10-30 /$ day] Duration $>10$ years in 36 cases, in 7 cases $<10$ years.

\section{Seasonal prevalence of chronic cor pulmonale:}

\begin{tabular}{|c|c|c|}
\hline NAME OF THE MONTH & NO.OF CASES & PERCENTAGE \\
\hline Jan & 10 & 20 \\
\hline Feb & 7 & 14 \\
\hline March & 8 & 16 \\
\hline April & 1 & 2 \\
\hline May & 2 & 4 \\
\hline June & 2 & 4 \\
\hline July & 4 & 8 \\
\hline August & 4 & 8 \\
\hline September & 3 & 6 \\
\hline October & 4 & 8 \\
\hline November & 1 & 2 \\
\hline December & 3 & 6 \\
\hline Table 4: Seasonal prevalemce of chronic cor pulmale
\end{tabular}

Table 4: Seasonal prevalence of chronic cor pulmonale

The table above reflects that chronic cor pulmonale is more in Jan, Feb, March months. Thus the peak occurrence was seen in winter months. 


\section{ORIGINAL ARTICLE}

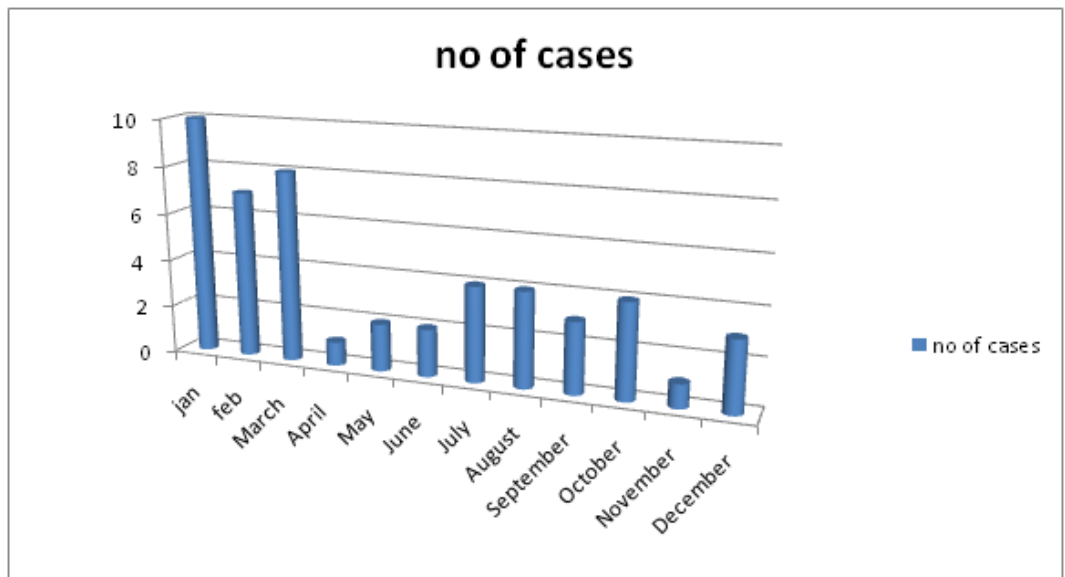

Graph 3: The seasonal prevalence of chronic cor pulmonale

\section{Duration of Symptoms:}

\begin{tabular}{|c|c|c|}
\hline Duration of symptoms & No of cases & Percentage \\
\hline$<1$ year & 0 & 0 \\
\hline $2-5$ & 26 & 52 \\
\hline $6-10$ & 16 & 32 \\
\hline $11-20$ & 6 & 12 \\
\hline$>20$ & 2 & 4 \\
\hline \multicolumn{2}{|c|}{ Table 5: Duration of Symptoms } \\
\hline
\end{tabular}

Suggesting that for development of chronic cor pulmonale, patient should have pulmonary disorder for some years.

\section{Symptoms:}

\begin{tabular}{|l|c|c|}
\hline \multicolumn{1}{|c|}{ Symptoms } & No of cases & Percentage \\
\hline Cough with expectoration & 50 & 100 \\
\hline Breathlessness & 50 & 100 \\
\hline Swelling of limbs & 47 & 94 \\
\hline Loss of appetite & 40 & 80 \\
\hline Pain abdomen & 36 & 72 \\
\hline Fever & 20 & 40 \\
\hline Haemoptysis & 12 & 24 \\
\hline Palpitations Table 6: Symptoms & 10 & 20 \\
\hline Chest pain & 8 & 16 \\
\hline \multicolumn{2}{|r|}{} \\
\hline
\end{tabular}

Cough with expectoration and breathlessness was present in all the patients, followed by swelling of the limbs, loss of appetite and pain abdomen. 


\section{General physical findings:}

\begin{tabular}{|l|c|c|}
\hline \multicolumn{1}{|c|}{ Signs } & No of cases & Percentage \\
\hline Cyanosis & 35 & 70 \\
\hline Clubbing & 10 & 20 \\
\hline Pedal edema & 47 & 56 \\
\hline
\end{tabular}

Table 7: General physical findings

Cyanosis was found in $70 \%$ of cases, pedal edema in $56 \%$ and clubbing in $20 \%$.

\section{Respiratory system findings:}

\begin{tabular}{|l|c|c|}
\hline \multicolumn{1}{|c|}{ Signs } & No of cases & Percentage \\
\hline Tachypnoea & 50 & 100 \\
\hline Barrel shaped chest & 40 & 80 \\
\hline Decreased chest expansion & 50 & 100 \\
\hline Decreased Breath sounds & 40 & 80 \\
\hline Rhonchi & 50 & 100 \\
\hline Crepatations & 50 & 100 \\
\hline \multicolumn{2}{|c|}{ Table 8: Respiratory system findings } \\
\hline
\end{tabular}

Tachypnoea, decreased chest expansion, rhonchi and crepatations were found in all the patients. Barrel chest and decreased breath sound s were noted in $80 \%$ of cases.

\section{Signs:}

\begin{tabular}{|l|c|c|}
\hline \multicolumn{1}{|c|}{ Signs } & No of cases & Percentage \\
\hline Raised JVP & 35 & 70 \\
\hline Left parasternal heave & 38 & 76 \\
\hline Dullness in left 2nd ICS & 30 & 60 \\
\hline Loud p2 & 45 & 90 \\
\hline Tricuspid regurgitation & 25 & 50 \\
\hline \multicolumn{2}{|c|}{ Table 9: Signs } \\
\hline
\end{tabular}

Loud p2 was noted I the majority of cases. Other systemic findings - 27 patients had hepatomegaly, 9 had ascitis and 2 had mental confusion.

\section{Causes (Etiology):}

\begin{tabular}{|l|c|c|}
\hline \multicolumn{1}{|c|}{ Causes } & No of cases & Percentage \\
\hline Chronic bronchitis with emphysema & 30 & 60 \\
\hline Bronchial asthma & 6 & 12 \\
\hline Bronchiectasis & 5 & 10 \\
\hline Old pulmonary tuberculosis & 6 & 12 \\
\hline Kyphoscoliosis Table 10: Causes \\
\hline \multicolumn{2}{|r|}{} \\
\hline
\end{tabular}


In $60 \%$ of the cases the cause was chronic bronchitis with emphysema. Bronchial asthma and old pulmonary TB, each was the cause in $12 \%$ of cases. Other cause were bronchiectasis and kyphoscoliosis.

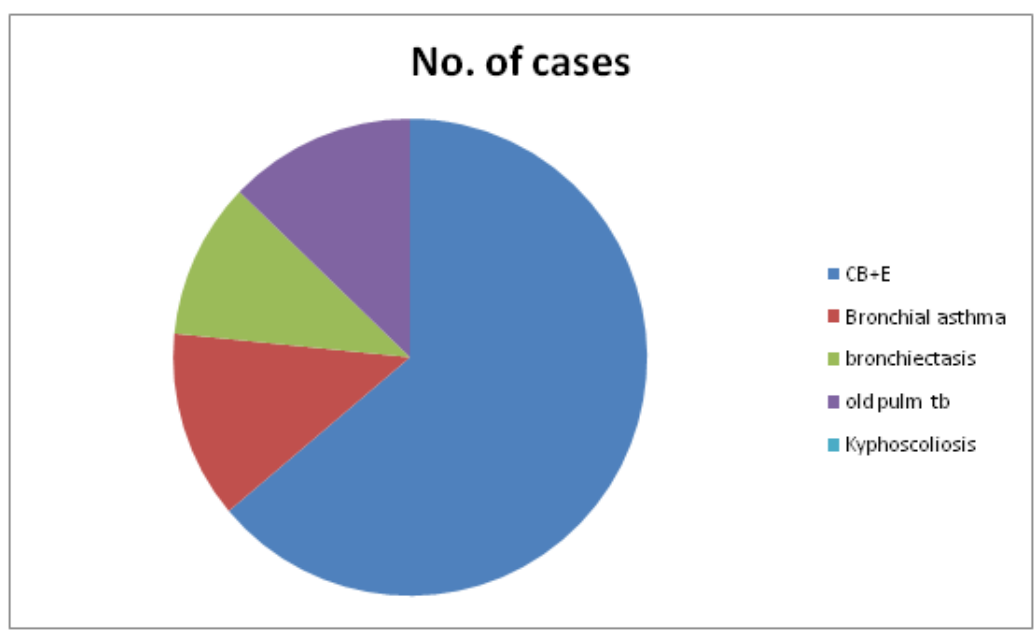

Graph 4: Causes

\section{Investigations:}

11a. Hematology: In most of the cases the hemoglobin percentage was between $8 \mathrm{gm} \%-14 \mathrm{gm} \%$ except in 2 patients where the hemoglobin was $5 \mathrm{gm} \%$, who required blood transfusion. The total leucocyte count was between 4,000 to 11,000 cells/cumm, 6 cases had counts >10,000 cells/cumm. ESR was raised in most of the cases.

11b. Urine Examination: Urine examination showed nothing abnormal except traces of albumin. In 1 patient 10 pus cells with 7-8 epithelial cells were found.

11c. Sputum examination: Sputum for AFB was done in patients with $X$ - ray suggestive of pulmonary Koch's. In 2 patients, sputum AFB was positive. Sputum for culture and sensitivity was done in every patient. In 38 patients the sputum culture was sterile. In 5 patients, the sputum culture showed Staphylococcus, 2 patients showed Klebsiella and 3 patients showed E-coli organisms.

\section{1d. Radiological Features:}

\begin{tabular}{|l|c|c|}
\hline \multicolumn{1}{|c|}{ Signs } & No of cases & Percentage \\
\hline Chronic bronchitis with emphysema & 30 & 60 \\
\hline Enlarged T D cardia & 20 & 40 \\
\hline Prominent pulmonary conus & 16 & 32 \\
\hline RDPA>16mm & 28 & 56 \\
\hline Bronchiectasis & 5 & 10 \\
\hline Old pulmonary tuberculosis & 6 & 12 \\
\hline Kyphoscoliosis Table 11: Radiological Features \\
\hline \multicolumn{2}{|c|}{} \\
\hline
\end{tabular}


$60 \%$ of cases had chronic bronchitis with emphysema features in chest X-ray. RDPA $>16 \mathrm{~mm}$ and enlarged T D cardia were found in $56 \%$ and $40 \%$ respectively.

\section{1e. ECG Findings:}

\begin{tabular}{|l|c|c|}
\hline \multicolumn{1}{|c|}{ Finding } & No of cases & Percentage \\
\hline P pulmonale & 35 & 70 \\
\hline Right axis deviation & 32 & 64 \\
\hline Right ventricular hypertrophy & 23 & 46 \\
\hline RBBB & 13 & 26 \\
\hline Low voltage complex & 25 & 50 \\
\hline Arrhythmias Table 12: ECG Findings \\
\hline \multicolumn{2}{|c|}{} \\
\hline
\end{tabular}

$\mathrm{P}$ pulmonale and right axis deviation were the most common findings. Other than findings mentioned in table, sinus tachycardia was present in 16 cases and ventricular ectopics in 6 cases, and atrial ectopics in 4 cases.

\section{1f. Pulmonary function test:}

\begin{tabular}{|l|c|c|}
\hline Type of abnormality & No of cases & Percentage \\
\hline Obstructive & 47 & 94 \\
\hline Restrictive & 3 & 6 \\
\hline \multicolumn{2}{|c|}{ Table 13: Pulmonary function test } \\
\hline
\end{tabular}

Obstructive abnormality was noted in $94 \%$ cases and restrictive only in $6 \%$.

\section{1g. Echocardiography:}

\begin{tabular}{|c|c|c|}
\hline RVIDED[m] & No of cases & Percentage \\
\hline $2.3-2.8$ & 0 & 0 \\
\hline $2.9-3.3$ & 7 & 14 \\
\hline $3.4-3.8$ & 25 & 50 \\
\hline$>3.8$ & 18 & 36 \\
\hline \multicolumn{2}{|c|}{ Table 14: Echo Findings } \\
\hline
\end{tabular}

Every patient showed enlarged right atrium and right ventricle with pulmonary artery hypertension either associated with trivial or moderate tricuspid regurgitation. Only 3 patients who were known case of COPD with hypertension showed global hypokinesia. 


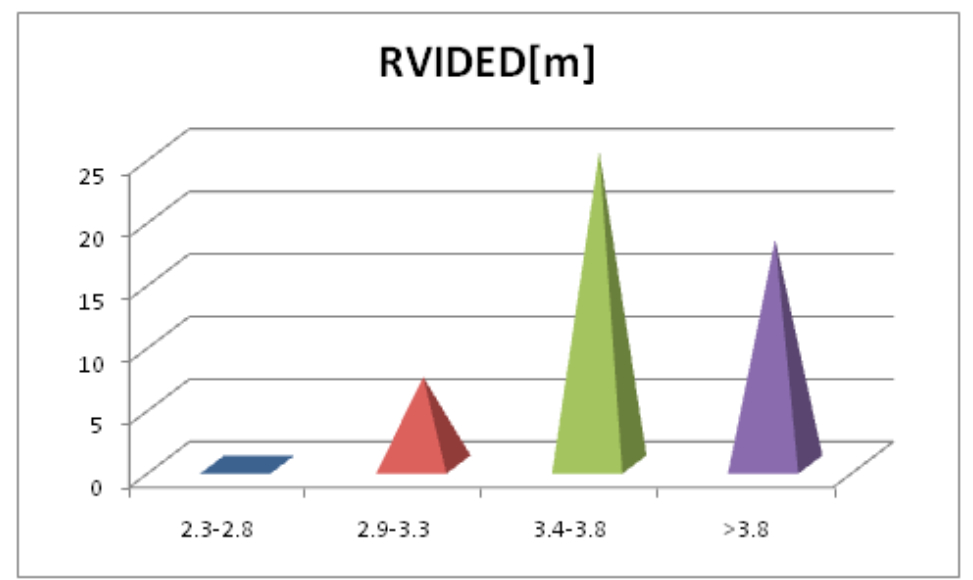

Graph 5: Echo Findings

DISCUSSION: The present study on chronic cor pulmonale can be discussed and compared under the following criteria.

In the present study the peak incidence was found to be in the $4^{\text {th }}, 5^{\text {th }}$ and $6^{\text {th }}$ decades of life and the age distribution is very well comparable with that of cases studied Padmavathi and Misra [1959] noticed maximum incidence between $40-49$ years. $^{8}$

Gupta et al [1989] reported a mean age of 50.2 plus or minus 12. 9

In the present study we also found that the incidence of cor pulmonale below the age of 40 was also increasing, this can be attributed to environmental pollution, as well as smoking habit earlier in life.

The study showed among 50 cases 45 was male and 5 were female. Various statistical studies have shown that chronic cor pulmonale is more common in mal es than in females.

\begin{tabular}{|l|c|c|}
\hline \multicolumn{1}{|c|}{ Study } & Male\% & Female\% \\
\hline Padmavathi[1959] & 54 & 46 \\
\hline Basavaraju urs and shankars[1965] & 83 & 17 \\
\hline Gupta et al.[1989] & 96 & 4 \\
\hline Present study & 90 & 10 \\
\hline \multicolumn{2}{|c|}{ Table 15: Sex distribution in various studies } \\
\hline
\end{tabular}

This difference in sex distribution is mainly due to smoking in males.

Bronchial asthma and chronic bronchitis are the main causes for the development of chronic cor pulmonale which were closely related to the patients' occupation. In the present study majority of the patients were coolie workers $46 \%$ and agriculturists $32 \%$. A study conducted by $\mathrm{R}$. Vishwanathan ${ }^{10}$ from 1963 to 1966, showed that 66 patients out off 130 were admitted after being exposed to smoke from fire places in which cow dung cake along with fire wood or coal were burnt. Smoke is no doubt a possible source of atmospheric pollution which can produce bronchial irritation in susceptible individuals. Indoor air pollution as a cause for COPD should also be considered. ${ }^{11}$

Smoking takes the credit as one of the major causative factor for COPD which results in chronic cor pulmonale. In the present study, 43 (86\%) male patients were smokers who used to 
smoke at least 10-12 beedies per day. The importance of smoking as a causative factor is well established in all the studies and various surveys conducted in United States and Great Britain.

\begin{tabular}{|l|c|}
\hline \multicolumn{1}{|c|}{ Authors } & Percentage \\
\hline Shankar et al (1965) & $80 \%$ \\
\hline Padmavathi et al & $70 \%$ \\
\hline Vishwanathan (1965 & $60 \%$ \\
\hline J.C. Banerjea (1963) & $17 \%$ \\
\hline Present study & $86 \%$ \\
\hline
\end{tabular}

Table 16: Smoking as an etiological factor

comparative percentage by various authors

Majority of patients in the study group presented during the winter months of the year. The exacerbations especially chronic bronchitis occur in winter months and they precipitate the ons et of heart failure in cases which have developed chronic cor pulmonale. ${ }^{11}$

In the present study $100 \%$ of the patients presented with breathlessness and cough. Many had peripheral edema and distension of the abdomen. Padmavathi et al. [1959] ${ }^{8}$ reported dyspnoea in $100 \%$, pedal edema in $90.4 \%$ and cyanosis in $83.2 \%$ of group.

Gupta et al [1989] noticed cyanosis in $50 \%$ of cases.

The present study showed $60 \%$ patients had chronic bronchitis and emphysema which was leading cause for chronic cor pulmonale.

\begin{tabular}{|l|l|c|}
\hline \multicolumn{1}{|c|}{ Authors } & \multicolumn{1}{c|}{ Cause } & Percentage \\
\hline Padmavathi et al & Chronic bronchitis with or without emphysema & $50.8 \%$ \\
\hline Kamat et al & Chronic bronchitis with or without emphysema & $62 \%$ \\
\hline Banerjea (1960) & Chronic bronchitis + bronchial asthma & $60.6 \%$ \\
\hline Vakil (1962) & Chronic bronchitis + bronchial asthma & $79.4 \%$ \\
\hline K. Vishwanathan (1965) & Chronic bronchitis and emphysema & $76.9 \%$ \\
\hline Banerjea (1963) & Chronic bronchitis and emphysema & $68 \%$ \\
\hline \multicolumn{2}{|r}{ Table 17: Etiological causes in various studies } \\
\hline
\end{tabular}

Thus reports of various authors and the present study show chronic bronchitis / emphysema as the major causative factor for chronic cor pulmonale.

In the present study chest $x$ - ray showed features according to the clinical profile. Majority of the chest $\mathrm{x}$-rays were suggestive of chronic bronchitis with emphysema (60\%) and cardiomegaly $(40 \%)$.

Regarding pulmonary fibrosis with other etiological factors as a cause of chronic cor pulmonale, the present study showed 6 cases (12\%) that showed $x$ - ray evidence of pulmonary tuberculosis with emphysema.

Pulmonary TB per se may not be considered as the sole cause of chronic cor pulmonale, emphysema due to cigarette smoking and occupational hazards are also contributory factors for lung damage. 
In a study by P.K. Jain et al (1978) showed 11 cases (8.8\%) out of 125 patients of pulmonary TB had clinical evidence of cor pulmonale in the form of congestive heart failure. ${ }^{12}$

2 patients (4\%) had gross thoracic deformity in the present study. These patients were prone for chronic cor pulmonale due to repeated respiratory infections and decreased lung compliance due to the deformity.

Among 50 patients studied 47 cases (94\%) showed $\mathrm{P}$ pulmonale and it had definite correlation with severity of chronic cor pulmonale and was found in majority of cases who had longer duration of illness.

\begin{tabular}{|l|c|}
\hline \multicolumn{1}{|c|}{ Series } & Percentage \\
\hline SPODICK 1959 & $13.9 \%$ \\
\hline CALATAYUD 1970 & $46.2 \%$ \\
\hline IVAN J PINTO & $32.32 \%$ \\
\hline CHAPPEL 1966 & $28 \%$ \\
\hline WOOD 1956 & $85 \%$ \\
\hline MATHUR 1966 & $49 \%$ \\
\hline PRESENT STUDY & $70 \%$ \\
\hline Table 18: Comparative percentage of P pulmonale in different series \\
\hline
\end{tabular}

In the present study 35 cases (70\%) showed ECG suggestive of right axis deviation.

\begin{tabular}{|l|c|}
\hline \multicolumn{1}{|c|}{ Series } & Percentage \\
\hline Padmavathi & $43.4 \%$ \\
\hline Pinto & $45,5 \%$ \\
\hline Mathur & $69 \%$ \\
\hline Vishwanathan & $15.3 \%$ \\
\hline Present study & $64 \%$ \\
\hline
\end{tabular}

\section{Table 19: Comparative percentage of right axis deviation}

In the present study 32cases (64\%) had ECG showing RBBB.

\begin{tabular}{|l|c|}
\hline \multicolumn{1}{|c|}{ Series } & Percentage \\
\hline Padmavathi & $7.2 \%$ \\
\hline Pinto & $13.3 \%$ \\
\hline Vishwanathan & $10.7 \%$ \\
\hline Present study & $26 \%$ \\
\hline
\end{tabular}

\section{Table 20: Comparative percentage of RBBB}

In comparison with the studies done by various authors the present study shows that ECG though it has its limitations can still be useful in diagnosing chronic cor pumonale. ECG can also be used as a negative prognostic sign in targeting COPD patients at risk of shorter survival. 
Echocardiography: the study showed mean RVIDED OF $3.52 \mathrm{cms}$, whereas in other studies conducted by Livo Bertolli et al [1983 and Gupta et al. [1989] showed 3.45cms and $2.97 \mathrm{cms}$ respectively, which is similar to our study.

CONCLUSION: The present study showed various clinical presentation and investigatory findings which are almost comparable to previous studies done by many authors. In the present study echocardiogram was found to be a better diagnostic tool when compared to electrocardiogram or chest $\mathrm{x}$ ray. Though echocardiogram has its own limitations to be considered in a patient with chronic obstructive lung disease, it is found to be useful in diagnosing accurately cases of occult cor pulmonale in recent studies. Thus chronic obstructive pulmonary disease resulting in chronic cor pulmonale constitutes a major burden in the rural population.

\section{SUMMARY:}

1. The objective of the study was to know the clinical profile, radiological features, electrocardiographic and echocardiographic changes in chronic cor pulmonale.

2. Among 50 cases in the study, 45 were males and 5 were females.

3. The peak incidence of chronic cor pulmonale was found to be in the middle and older age groups ( $4^{\text {th }}, 5^{\text {th }}$ and $6^{\text {th }}$ decade $s$ of life).

4. Chronic cor pulmonale patients were admitted more commonly in the winter months of the year (January and February).

5. Smoking was found to be an important factor in precipitating or aggravating the primary lung disease and hence cor pulmonale. Out of 50 cases 43 were found to be smokers in the present study.

Many patients were farmers and coolie workers, thus dusty environment at the site of occupation was also found be an additional factor in aggravating the primary lung disease.

6. With respect to the presenting complaints breathlessness, cough and edema of the feet were the most common symptoms.

7. In the present study 5 cases were found to have bronchiectases, 6 cases had bronchial asthma, 6 cases had pulmonary tuberculosis and 3 cases had kyphoscoliosis. The rest of the cases were diagnosed to have chronic bronchitis with or without emphysema.

8. Routine blood examination, urine routine, sputum for AFB and culture was done in every patient.

9. Chest $\mathrm{x}$ - ray showed details relevant to the clinical profile. $60 \%$ of the patients showed chest $\mathrm{x}$ ray suggestive of chronic bronchitis with or without emphysema. $40 \%$ showed evidence of cardiomegaly with or without signs of pulmonary hypertension. $10 \%$ of patients had x- ray evidence of bronchiectasis (bilateral or right/left). 12\% showed evidence of bilateral pulmonary tuberculosis and $6 \%$ of patients showed kyphoscoliosis with gross thoracic cage deformity.

10. Electrocardiogram showed changes from normal to right ventricular hypertrophy. The present study showed $46 \%$ cases with RVH, 64\% RAD, 26\% RBBB and 70\% with P pulmonale.

11. In echo, all patients showed clear evidence of features suggesting chronic cor pulmonale. Thus echo was a better diagnostic tool when compared to ECG in the present study. 


\section{BIBILIOGRAPHY:}

1. Sandeep Singh. Cor pulmonale. In: YP Munjal, editor. API Text Book of Medicine. 9th ed. Mumbai: The Association of Physicians of India; 2012.p.1798-1802.

2. Bhargava RK. Cor pulmonale (Pulmonary Heart Disease). New York USA: Futura publishing company; 1973.

3. White J, Bullock RE, Hudgson P, Gibson GJ. Neuromuscular disease, Respiratory failure and Cor pulmonale. Postgraduate Med J 1992; 68: 820-823.

4. Douglas L. Mann, Murali Chakinala, Heart failure and Cor pulmonale. In: Kasper DL, Fauci AS, Longo DL, Hauser, Longo, Jameson JL, Loscalzo. Editors. Harrison's principles of Internal medicine. 18t h ed. Vol-2. New York: McGraw-Hill; 2012.p.1913-1915.

5. Chronic cor pulmonal. Report of an expert committee. CLINICAL PROGRESS. Circulation vol xxvii apr 1963; 59-614.

6. Calvelrly PM, Cattrall JR, Shapiro C, Douglas NJ. Cor pulmonale in asthma. Br, J Dis Chest 1983 Jul; 77(3); 303-7.

7. Paules RA, Buist AS, Calverly PMA, et al. on behalf of the GOLD scientific committee. Global strategy for the diagnosis, management and prevention of chronic obstructive pulmonary diseases. NHLBI/WHO global initiative for chronic obstructive lung disease \{GOLD\}workshop summary. Am J Respir Crit Care Med 2001;163:1256-1276.

8. Padmavathi S.: "Chronic cor pulmonale in INDIA". Physiol. Med. Sci. India, 2:27, 1958.

9. John B, Pier G, Agaston. Cor pulmonale. In: Murray Nadel, editor. Text Book of Respiratory Medicine. 2nd ed. Vol-2. Philadelphia : W.B Saunders company; 1988.p.1779-1798.

10. Vishwanathan K. Chronic Cor pulmonale. Ind J Chest Dis 1965; 7(4):155-169.

11. Tripathi KD, editor. Essentials of medical pharamcology. 4t h ed. New Delhi: Jaypee Brothers ; 2000.

12. Jain PK, Singh RG, Agarwal BV, Jha VK. Significance of right sided electrocardiographic leads in the diagnosis of cor pulmonale in pulmonary tuberculosis. Ind J chest Dis Allied Sci 1978;20(3):112-117.

13. Senior RM, Stapiro SD. Chronic obstructive pulmonary disease: epidemiology, pathophysiology and pathogenesis. In: Fishman AP, Elisa JA, Grippi MA, Kaiser LR, Senior RM, editors. Fishman's Pulmonary Disease and Disorders. 3rd ed.Vol-1. New York: McGraw Hill; 1998. p. 659-681.

14. Rich S, Mclaughlin VU. Pulmonary Hypertension. In: Zippes DP, Libby P, Bonow RO Braunwald E, editors. Braunwald's Heart Disease: A Text Book of Cardiovascular Medicine. $8^{\text {th }}$ ed. USA: Elsevier Saunders; 2005.p.1807-1845.

15. Reilly JJ, Silverman EK, Shapiro SD. Chronic obstructive pulmonary disease. In: Kasper DL, Fauci ASLongo DL, Braunwald E, Hauser SL, Jameson JL, editors. Harrison's Principles of Internal Medicine. 16t h ed.Vol-2. New York: McGraw Hill; 2005. p 1547-1554.

16. Newman JH. Chronic Cor pulmonale. In: Fuster V, Al exander RW, O Rourke RA, Roberts R, King SR, Wellen HJJ, editors. Hurst's the Heart. 10th ed. Vol.2. USA: McGraw Hill; 2001.p.1645-1654. 


\section{AUTHORS:}

1. Sunil Babu M.

2. Praveen N.

3. Vasudev Naik

\section{PARTI CULARS OF CONTRIBUTORS:}

1. Assistant Professor, Department of General Medicine, Adichunchanagiri Institute of Medical Sciences.

2. Assistant Professor, Department of General Medicine, Adichunchanagiri Institute of Medical Sciences.

3. Professor \& HOD, Department of General Medicine, Adichunchanagiri Institute of Medical Sciences.

\section{NAME ADDRESS EMAIL ID OF THE}

\section{CORRESPONDING AUTHOR:}

Dr. Sunil Babu M., 90/ Neela Nivas,

M.C. Road, Vijayanagara,

Bangal ore - 40 .

Email - doctor_sunil62@yahoo.com

Date of Submission: 15/10/2013.

Date of Peer Review: 16/10/2013.

Date of Acceptance: 31/10/2013.

Date of Publishing: 07/11/2013 